\title{
Foreign Body Granuloma
}

\author{
Sequiera Joyce $\cdot$ B. H. Rao Sripathi $\cdot$ \\ Mathew O. Mampilly $\cdot$ C. S. Firdoose Nyer
}

Received: 23 March 2010/Accepted: 14 October 2010/Published online: 25 March 2011

(C) Association of Oral and Maxillofacial Surgeons of India 2011

\begin{abstract}
Foreign bodies can penetrate soft tissues through open wounds, lacerations or through accidents iatrogenically. Among the commonly encountered foreign bodies encountered due to trauma are of glass, metal and wood in nature. We report a case of a 32 year old male who reported to our clinic, complaining of a small wound in the right upper cheek region intraorally since 1 month. Patient had a history of road traffic accident (RTA) 6 months back.
\end{abstract}

Keywords Foreign body - Foreign body granuloma

\section{Introduction}

Penetration of foreign bodies may present a diagnostic challenge to the surgeon. Approximately all foreign bodies are initially missed. In case of wooden foreign body only $15 \%$ are well visualized on plain radiographs and are therefore often missed or misdiagnosed [1]. Foreign bodies may be ingested or embedded into the body due to traumatic or iatrogenic injury [2]. Foreign bodies causes abscess formation, septicemia or lead to secondary hemorrhage. They can also undergo distant embolization. RTA road traffic accidents assaults and bullet injuries are common causes of traumatic foreign bodies [2, 3]. We are reporting an interesting case of a foreign body in the oral cavity which presented as a granuloma.

S. Joyce $(\bowtie) \cdot$ B. H. Rao Sripathi · M. O. Mampilly •

C. S. Firdoose Nyer

Department of Oral and Maxillofacial Surgery, Yenepoya Dental College and Hospital, Mangalore 575018, Karnataka, India

e-mail: joycemathias26@yahoo.com

\section{Case Report}

A 32 year old male reported to the department of Oral and Maxillofacial Surgery in October 2009, with a complaint of a small wound on the right upper lip intraorally since 1 month and also complained of a swelling in the right upper cheek region associated with difficulty in speaking. Patient gave a history of road traffic accident (RTA) 6 months back. Following the injury, there was no loss of consciousness. However multiple lacerations on the face and lips were noticed. The patient was admitted to local hospital for four days where the multiple lacerations on the face and lips were sutured primarily. The wound on the upper labial mucosa appeared four months after the trauma.

\section{Clinical Examination}

On extra oral examination facial asymmetry with obliteration of right nasolabial fold with diffuse swelling was seen below and adjacent to right alae of the nose (Fig. 1). Skin over the swelling was similar to the adjacent area with no discharge or ulceration. Scar marks were visible on the lateral border of the right side of the root of the nose, left side of the lower on the right cheek.

On intraoral examination there was a nodular growth of size $3 \times 3 \mathrm{~cm}$ present on the labial aspect of the upper lip in relation to 12,13 , and $14 \mathrm{lip}$ and on the left lateral supraorbital margin. On palpation there was tenderness over the swelling. The nodular growth appeared yellowish in color surrounded with red erythematous and papillary growth in the periphery (Fig. 2). Bleeding with exudation was observed over the mucosa and nodular growth.

IOPA in relation to $13 \& 12$ showed loss of lamina dura with ill defined radiolucency peri apically in relation to 12 . 


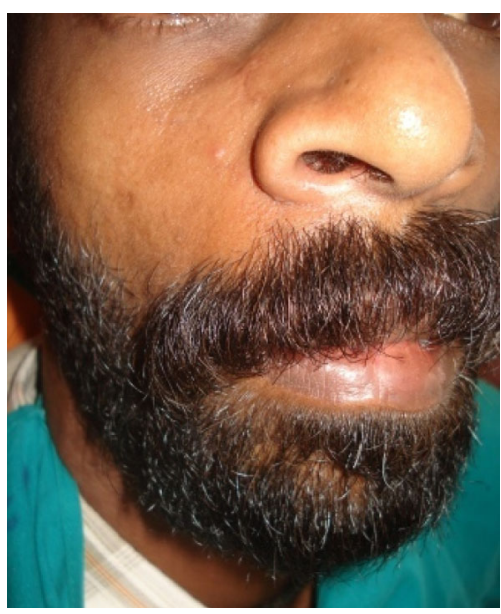

Fig. 1 Extra oral appearance

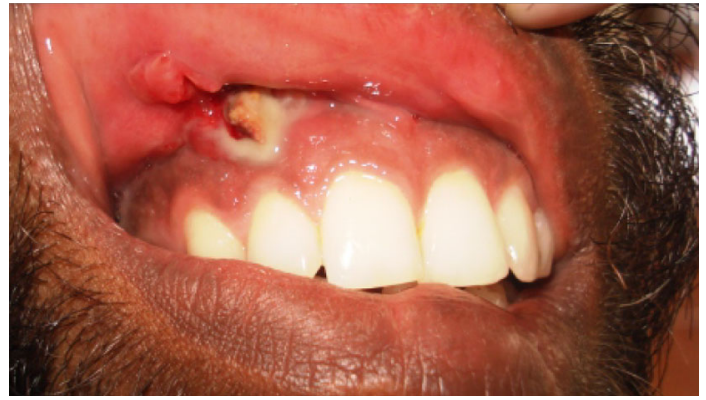

Fig. 2 Intraoral appearance

\section{Differential Diagnosis}

Foreign body granuloma

Periapical abscess

Carcinoma of the alveolus

\section{Surgical Management}

An infraorbital nerve block was given and the mobile segment was pulled out which was an embedded wood piece of $3.2 \times 0.5 \mathrm{~cm}$ in size (Fig. 3). An incision was placed on the nodular growth adjacent to the labial vestibule to gain access (Fig. 3) to the wooden piece and on further exploration another wood piece of size $3 \times 0.5 \mathrm{~cm}$ was dissected out, along with this 2-3 small wood pieces was retrieved. A small portion of tissue was excised for histopathological examination. Site was thoroughly explored and debrided and made sure no more wood pieces were left behind (Figs. 4, 5). The cavity was thoroughly irrigated with antiseptic solution and the wound was sutured primarily (Fig. 6). Patient was put on antibiotics and analgesics and was followed up for 3 weeks. The labial swelling had subsided and patient was able to speak

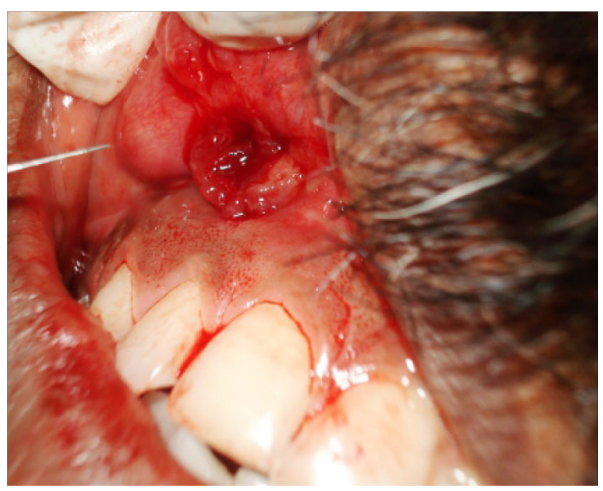

Fig. 3 Intraoral incision

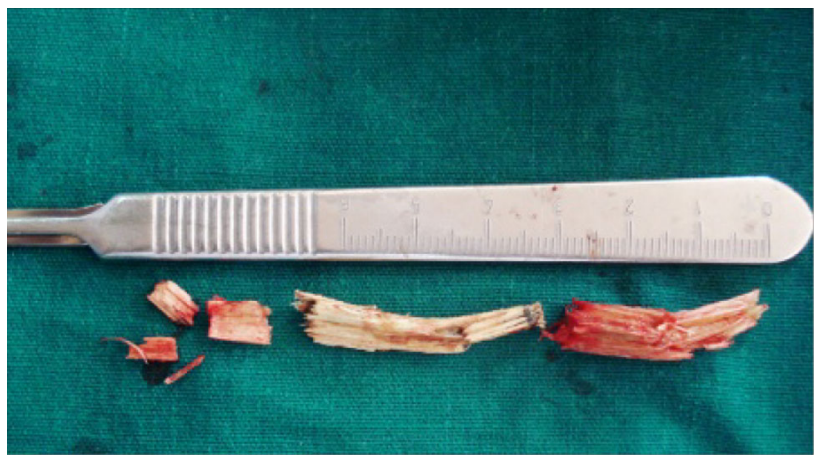

Fig. 4 Retrieved foreign body

properly. Post operatively wound healing was uneventful (Figs. 7-9).

\section{Discussion}

Foreign bodies in the head and neck are common, including those of long duration. They can be detected as a radiographic finding in a routine examination and a painless reaction is, sometimes, a feature of this lesion, making diagnosis more difficult.

The visibility of different materials on plain radiographs depends on their ability to attenuate X-rays. Foreign bodies may be visualized depending on their inherent radio density and proximity with the tissue in which they are embedded. Plain radiographs are not useful and CT scanning may not distinguish plastic material from soft tissues [4]. Depending on their relative densities although it may show signs of infection or other chronic reactions. MRI is probably the imaging technique with which to locate plastic foreign bodies embedded in soft tissues [1, 3, 5].

Metallic objects, unless made of aluminium are opaque on radiographs, as are most animal bones and all glass foreign bodies. In patients who have had a penetrating 


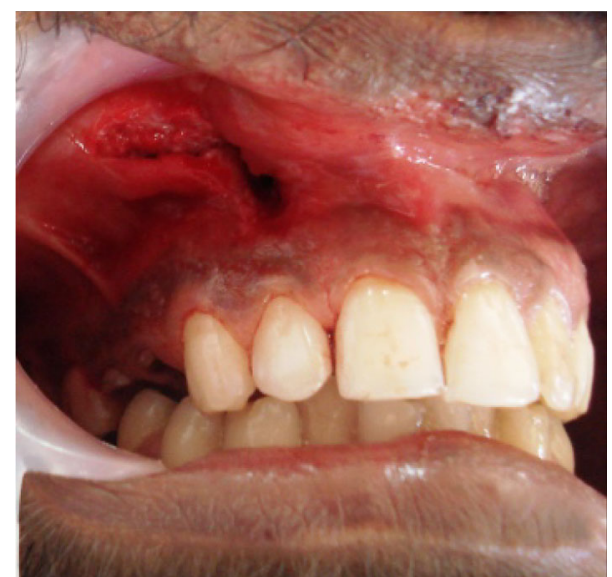

Fig. 5 Wound after the removal of wood piece

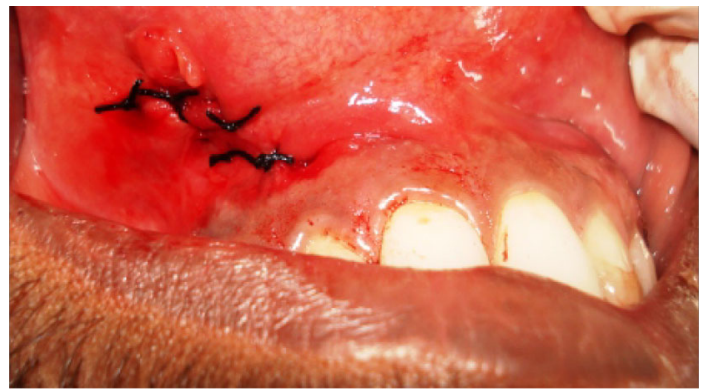

Fig. 6 Wound closure done with 3-0 mersilk

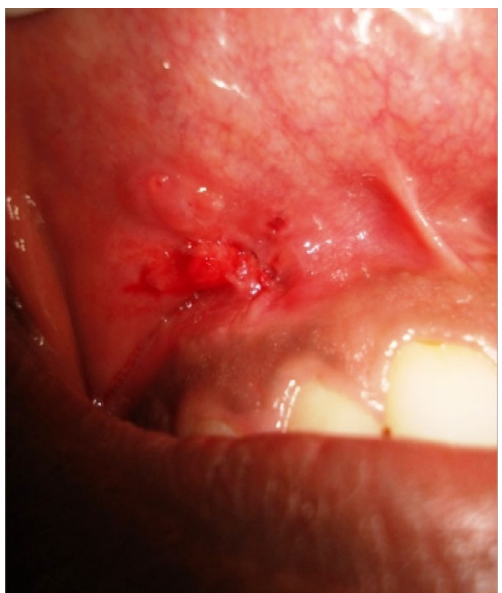

Fig. 7 Intra oral appearance after 1 week of healing

injury, nature of foreign body determines the clinical behavior. Inert object such as steel and glass may not cause significant inflammation. Removal of organic foreign bodies such as wood piece and fish bones is mandatory because they provide a good medium for microbial agents and this usually leads to secondary infection with abscess and fistula formation [7]. Two basic categories of etiologic factors are recognized as inducers of granulomatous

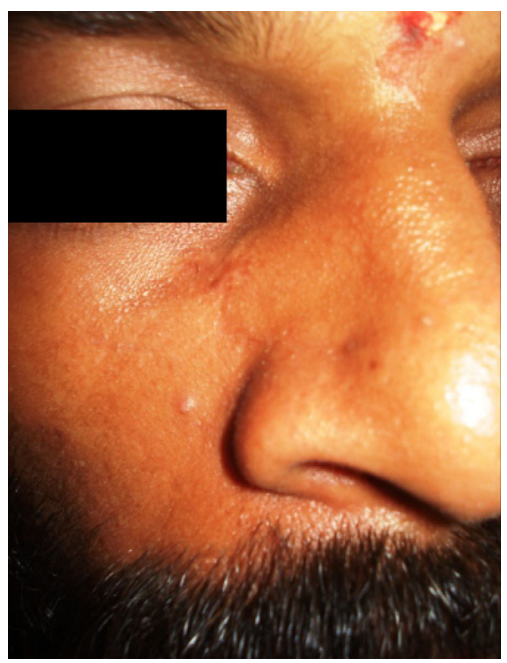

Fig. 8 Postoperative view after 1 week

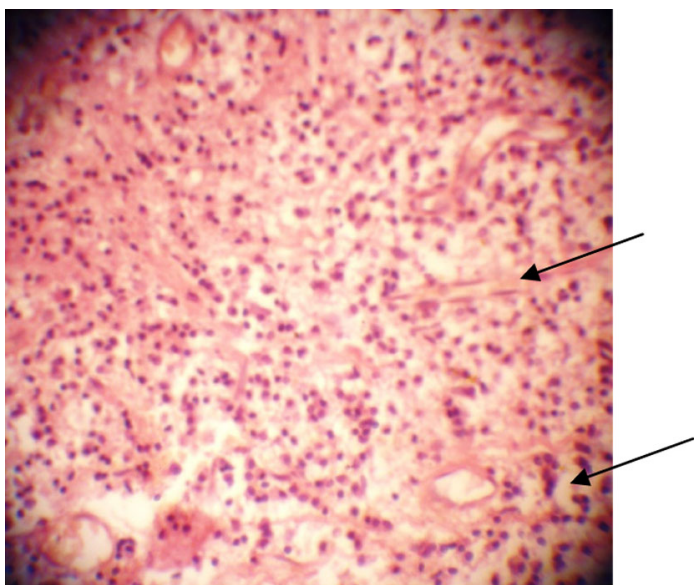

Fig. 9 Histological view under microscope showing granulation tissue exhibiting proliferation of fibroblasts and endothelial cells with few multinucleated giant cells

inflammatory responses. The first comprises inert substance that are unable to incite any specific inflammatory or immune response. These are artificially termed foreign body typed agents and although non-immunogenic, their chemical properties render them able to generate granulomas which differ in evolution, dynamics, duration, severity and involution rates from infectious type [11].

In our case the foreign body penetrated and was deeply embedded in the infraorbital region into the oral cavity. The secondary infection was noticed four months after the trauma. Since wood was radiolucent the diagnosis was of periapical abscess. So this emphasizes the need for taking proper history and thorough debridement and exploration of the wound before doing a primary closure. Histopathologically the presence of granulation tissue exhibiting proliferation of fibroblasts and endothelial cells with mixed inflammatory infiltrate consisting of lymphocytes, plasma 
cells, histiocytes, few polymorphonuclear leucocytes \& few giant cells, correlating with clinical history were suggestive of a foreign body granuloma (Fig. 9).

Confocal laser scanning is a newer method of identifying the microscopical changes within the tissues where the foreign body is embedded. It helps in providing improved tissue images, bi-dimensional pictures with better resolution at cellular level and in particular a three dimensional imaging and reconstruction is possible [13].

\section{References}

1. Krimmel M, Cornelius CP, Stojadinovic S, Hoffmann J, Reinert S (2001) Wooden foreign bodies in facial injury: a radiological pitfall. Int J Oral Maxillofac Surg 30:445-447

2. Sumanth KN, Boaz Karen (2008) Glass embedded in labial mucosa for 20 years. Indian J Dent Res 19(2):160-161

3. Stewart CM, Watson RE (1990) Experimental foreign body reactions: commonly employed dental materials. Oral surg Oral Med Oral Pathol 69:713-719

4. Robinson PD, Rajayogeswaran V (1997) Unlikely foreign bodies in unusual facial sites. Br J Oral Maxillofac Surg 35:36-39
5. McCaughey AD (1988) An Unusual infraorbital foreign body. Br J Oral Maxillofac Surg 26:426-429

6. Westermark AH (1989) Spontaneous removal of foreign bodies from the maxillary sinus. Br J Oral Maxillofac Surg 47:75-77

7. Henry RC (1971) Infra orbital penetrating foreign body. Br J Oral Surg 8:192

8. Krishnan A (1992) Trismus caused by a retained foreign body in an adult. Oral surg, Oral Med Oral Pathol 73:546-547

9. Silva EJD, Deng Y (2000) An unusual foreign body in the tongue. Br J Oral Maxillofac Surg 38:241-242

10. Law S, Watters GW (1997) Penetrating oral foreign body presenting as an aural polyp. J Laryngol Otol 3111:749-751

11. Mariano M (1995) The experimental granuloma. A hypothesis to explain the persistence of the lesion. Rev Inst Med Trop Sao Paulo 37(2):161-176

12. McDonnell DG, McKierman EY (1986) Broken tooth fragments embedded in the tongue. $\mathrm{Br} \mathrm{J}$ Oral Maxillofac Surg 24(6):464-466

13. Michele S, Alberta L (2009) Oral pulse granuloma: histological findings by confocal laser scanning microscopy. Ultrastruct Pathol 33(4):155-159

14. Silveira VAS, do Carmo ED, Colombo CED, Cavalcante ASR, Carvalho YR (2008) Intraosseous foreign body granuloma in the mandible subsequent to a 20-year-old-work-related accident. Med Oral Patol Oral Cir Bucal 13(10):E657-E660 